Informal Logic

VII.1, Winter 1985

\title{
McPeck's Mistakes
}

\author{
RICHARDW. PAUL Sonoma State University
}

Critical Thinking and Education by John E. McPeck. Martin Robinson, Oxford, 1981.

Most educational commentators and most of the general public seem to agree on at least one thing: the schools are in deep trouble. Many graduates, at all levels, are characterized as lacking the abilities to read, write, and think with a minimal level of clarity, coherence, and critical/analytic exactitude. Most commentators agree as well that a significant part of the problem is a pedagogical diet excessively rich in memorization and superficial rote performance and insufficiently rich in, if not devoid of, autonomous critical thought. This complaint is not entirely new in American education but the degree of concern and the growing but quiet revolution represented by those attempting to meet that concern is worthy of note. (A recent ERIC computer search identified 1,849 articles in the last seven years with critical thinking as a major descriptor. [1]) The roots of this multi-faceted movement can be traced back in a number of directions, but one of the deepest and most important goes back as far as Ed Glaser's An Experiment in the Development of Critical Thinking (1941) (and his establishing with Watson of the Watson-Glaser Critical Thinking Test) and Max Black's Critical Thinking (1946). The manner in which this root of the movement has, after a halting start, progressively built up a head of steam, has been partially chronicled by Johnson and Blair. [2] It is now firmly established at the college and university level effecting there an increasing number of courses that focus on "Critical Thinking" or "Informal Logic," courses designed to provide the kind of shot-inthe-arm for critical thinking that general composition courses are expected to provide for writing. [3] The influence of this current in the movement is being increasingly felt at lower levels of education but in a more variable, if somewhat less effective way.

At this point enter John McPeck with. his book Critical Thinking and Education which promises us (on its dust jacket) "a timely critique of the major work in the field," "rigorous ideas on the proper place of critical thinking in the philosophy of education," "a thorough analysis of what the concept is," as well as providing "a sound basis on which the role of critical thinking in the schools can be evaluated." The book is important not only because it is the first to attempt a characterization of the recent critical thinking movement, but more so because the foundational mistakes it makes are uniquely instructive, mistakes so eminently reflective of "the spirit of the age" they are likely to show up in many more places than this book alone. Unfortunately, because of serious 
flaws in its theoretical underpinnings, the book doubtless will lead some of McPeck's readers down a variety of blind alleys, create unnecessary obstacles to some important programs being developed, and encourage some - not many, I hope-to dismiss the work of some central figures in the field (Scriven, D'Angelo, and Ennis most obviously). At the root of the problem is McPeck's (unwitting?) commitment to a rarefied form of logical (epistemological) atomism, a commitment which is essential if he is to rule out, as he passionately wants to, all general skills of thought and so to give himself a priori grounds to oppose every and all programs that try to develop or enhance such skills.

McPeck's "mistakes" are, from one vantage point, glaring and fundamental; from another they are seductive, and, as I have suggested above, quite "natural." They bear examination from a number of points of view. Certainly there are few who would not see the fallacy in inferring that, because one cannot write without writing about something, some specific subject or other, it is therefore unintelligible "muddled nonsense" to maintain general composition courses or to talk about general, as against subjectspecific, writing skills. Likewise most would think bizarre someone who argued that because speech requires something spoken about, it therefore is senseless to set up general courses in speech and incoherent to talk of general speaking skills.

Yet McPeck's keystone inference, logically parallel and equally fallacious in my view, is likely to be seductively attractive to many teachers and administrators in the form in which McPeck articulates it:

... it is a matter of conceptual truth that thinking is always thinking about $X$, and that $X$ can never be 'everything in general' but must always be something in particular. Thus the claim ' $I$ teach my students to think' is at worst false and at best misleading.

Thinking, then, is logically connected to an $X$. Since this fundamental point is reasonably easy to grasp, it is surprising that critical thinking should have become reified into a curriculum subject and the teaching of it an area of expertise of its own...

... In isolation it neither refers to nor denotes any particular skill. It follows from this that it makes no sense to talk about critical thinking as a distinct subject and that it therefore cannot profitably be taught as such. To the extent that critical thinking is not about a specific subject $X$, it is both conceptually and practically empty. The statement 'I teach critical thinking', simpliciter, is vacuous because there is no generalized skill properly called critical thinking. (pp. 4 and 5)

Many would, I suspect, find it equally attractive to conclude with McPeck that "the real problem with uncritical students is not a deficiency in a general skill, such as logical ability, but rather a general lack of education in the traditional sense" and that "... elementary schools are fully occupied with their efforts to impart the three $R^{\prime} s$, together with the most elementary information about the world around them" and hence have no time to teach critical thinking as well. They might not be as comfortable with his notion that "there is nothing in the logic of education that requires that schools should engage in education" and "nothing contradictory in saying 'This is a fine school, and I recommend it to others, even though it does not engage in education." "'

Still, this latter point is mentioned only once and not endlessly repeated in an array of different forms as in his major refrain that "thinking of any kind is always about $X$." The " $X$ " of this refrain, that to which $M c P e c k$ believes the logic of all thought is to be relativized, is itself characterized in a litany of synonyms ("the question at issue," 
"the subject matter," "the parent field," "the field of research," "the specific performance," "the discipline," "the cognitive domain," and so forth) as are the various criteria (the need for "specialized and technical language," "technical information," "field-dependent concepts," "unique logic," "unique skills," "intra-field considerations," "subject-specific information," and so forth) imposed on the critical thinker by the $X$ in question. The hypnotic effect of the continual reiteration of the truism implicit in his major refrain alongside of a variety of formulations of his major conclusion is such that readers not used to slippery non-sequiturs are apt to miss the logical gap ex praemissis conclusio.

If nothing else the reader is bound to feel something of the attractiveness in this technological/specialists' world of ours-of McPeck's placing of critical thought squarely in the centre of an atomistic, information-centered model of knowledge. We are already comfortable with the notion that to learn is to amass large quantities of specialized or erudite facts and we know that facts are of different types. We tend in other words to think of knowledge on the model of the computers we are so enamored of: on the one hand, a huge mass of atomic facts (our data bank), and on the other a specific set of categories, McPeck's logical domains, which organize them into higher-order generalizations by formulas and decision-procedures of various kinds. To change one of the formulas or decision-procedures requires technical information about the facts to be manipulated. Critical thought in this context requires understanding of both the data bank and the established procedures.

But it is well to remember that we cannot ask computers multi-categorical questions, especially those kinds that cut across the disciplines in such a way as to require reasoned perspective on the data from a "global" point of view. Such questions, structuring the very warp and woof of everyday life, are typically dialectical, settled, that is, by general canons of argument, by objection (from one point of view) and reply (from another), by case and countercase, by debate not only about the answer to the question but also about the very logic of the question itself. Most social and world problems are of this nature, as well as those that presuppose the subject's world view. For example, consider those social problems that call for a judgment of the equity of the distribution of wealth and power, of the "causes" of poverty, of the justification and limits of welfare, of the nature, or existence, of the militaryindustrial complex, of the value or danger of capitalism, of the character of racism and sexism or their history and manifestations, of the nature of communism or socialism,... The position we take on any one of these issues is likely to reflect the position we take on the others and they are all likely to reflect our conception of human nature (the extent of human "equality" and what "follows" from it as so conceived, the nature and causes of human "laziness" and "ambition"), the need for "social change" or "conservatism," even the character of the "cosmos" and "nature."

This point was brought home to me recently when $\mathbf{I}$ got into a lengthy disagreement with an acquaintance on the putative "justification" of the American invasion of Grenada. Before long we were discussing questions of morality, the appropriate interpretation of international law, supposed rights of countries to defend their interests, spheres of influence, the character of the U.S. and Soviet foreign policy, the history of the two countries, the nature and history of the C.I.A., the nature of democracy, whether it can exist without elections, who has credibility, how to judge it, the nature of the media, how 
to assess it, whether it reflects an "American" party line, sociocentrism, our own personalities, consistency, etc. Especially illuminating and instructive was the distinctive pattern that these discussions took. It was eminently clear that we disagreed in our respective world views, our global perspectives. Because we each conceived of the world with something like an integrated point of view, we conceptualized the problem and its elements differently. Specialized information was differently interpreted by us. There were no disciplinespecific skills to save the day.

McPeck avoids commenting on such problems except insofar as they presuppose specialized information, which he then focuses on. From a logical atomist's point of view (everything to be carefully placed in an appropriate sui generis logical category, there iø to be settled by appropriate specialists in that category) dialectical, multi-categorical questions are anomalous. When noticed the tendency is to try to fabricate specialized categories for them or to break them down into a summary complex of mono-categorical elements. Hence the problem of peace in relation to the military-industrial complex would be broken down by atomists into discrete sets of economic, social, ethical, historical, and psychological problems, or what have you, each to be analyzed and settled discretely. This neat and tidy picture of the world of knowledge as a specialist's world is the Procrustean Bed that McPeck has prepared for critical thought. To aspire to critical thought, on this view, is to recognize that it can be achieved only within narrow confines of one's life ("... there are no Renaissance men in this age of specialized knowledge," p. 7). It is possible only in those dimensions where one can function as a "properly trained physicist, historian... [or] art critic,"' (p. 150), etc., and so learn specialized knowledge and unique skills.
McPeck identifies the bogey man in critical thinking in a variety of ways ("the logic approach," "formalism," "informal logic," "naive logical positivism," "logic simpliciter," and so forth) but the bulk of his book is spent in attacking scholars associated with the informal logic movement (Ennis, Johnson, Blair, D'Angelo, and Scriven). The general charge against them is, predictably, that they have failed to grasp what follows from the logic of the concept of critical thinking - that it is "muddled nonsense" to base it on general skills-and that such misguided attempts necessarily result in "the knee-jerk application of skills" and "superficial opinion masquerading as profound insight," and are thus bound to run aground.

Since McPeck rests so much on his conceptual analysis, it is appropriate to note what he leaves out of it. He does not consider the full range of uses of the word 'critical' as they are relevant to various everyday senses of the predicate 'thinks critically.' He does not consider the history of critical thought, the various theories of it implicit in the work of Plato, Aristotle, Kant, Hegel, Marx, Freud, Weber, Sartre, Habermas, and so forth. He does not consider the implications of such classic exemplars as Socrates, Voltaire, Rousseau, Thomas Paine, Henry David Thoreau, or even of an H.L. Mencken, or Ivan Illich, to mention a few that come to mind, whether, that is, their critical thinking can or cannot be explained by, or reduced to, specialized knowledge or domain-specific skills. He does not consider the rich range of programs that have been developed in the recent work in the field (he has it in mind that in principle there cannot be a field of research here). He does not consider the possibility that in the light of the rich variety of programs, reflecting somewhat different emphases, interests, priorities, it may be premature to attempt to pin down in a few words 
"the concept of critical thinking." He does not consider the possibility that the scholars he is criticizing may be using the term in an inductive sense, hence not, presupposing or claiming a definitive analysis of the concept, but restricting their focus rather to some of its necessary, not sufficient, conditions (for example: aiding students in developing greater skill in identifying and formulating questions at issue, distinguishing evidence from conclusion, isolating conceptual problems and problems of credibility, recognizing "common" fallacies, and coming to a clearer sense of what a claim or an assumption or an inference or an implication is and so forth).

One result is that his analysis of "the concept of critical thinking" is in all essentials completed in the first 13 pages of the book with his foundational inference in place by page four. Another is that he gives a most unsympathetic and at times highly misleading representation of most of those he critiques (Ennis, Glaser, D'Angelo, Johnson, Blair, and Scriven).

In order to have space to develop the broader implications of McPeck's anaIysis, I will illustrate this latter tendency solely with respect to Robert Ennis, who is at the centre of most of his critical remarks in chapter three, "The Prevailing View of the Concept of Critical Thinking." McPeck introduces this chapter with three interrelated general charges about the "theoretical foundation" of the prevailing concept: that those who hold it subscribe "to the verifiability criterion of meaning," are "marked by a naîve form of logical positivism," and have "an unquestioned faith in the efficacy of science and its methods to settle every significant controversy requiring critical thought." However, nowhere in the chapter does he back up these charges. And I myself do not find anything in the work of Ennis (or of D'Angelo for that matter) that suggests such a theoretical com- mitment

McPeck focuses his critique on Ennis's article, "A Concept of Critical Thinking," published in 1962, despite the fact that Ennis has been regularly publishing and.modifying his position to date. Secondly, it is clear that Ennis, even in this early article, does not take himself to be providing a definitive analysis of the concept; he offers but a "truncated" working definition. He describes his article as providing a "range definition" which has "vague boundaries," based on an examination of "the literature on the goals of the schools and the literature on the criterion of good thinking," and designed merely to "select" "those aspects" which come under the notion of critical thinking as "the correct assessing of statements." He makes it clear that he is leaving out at least one crucial element ("the judging of value statements is deliberately excluded"). He makes clear that his working definition does not sețtle the question as to how best to teach critical thinking, e.g., whether as a separate subject or within subject areas. Finally, it is clear that he is concerned with critical thinking as an open-ended and complicated set of processes that can be set out in analyzed form only for the purpose of theoretical convenience, a list of "aspects" and "dimensions" that can be learned "at various levels." [4]

McPeck's motive for critiquing Ennis's concept is clearly the fact that Ennis does not define critical thinking so as to link it "conceptually with particular activities and special fields of

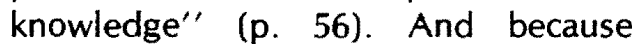
McPeck sees this conceptual link as necessary, as given in the concept, it is, on his view, "impossible to conceive of critical thinking as a generalized skill" (p. 56). In other words, Ennis is conceiving of critical thinking in an "impossible" and therefore incoherent, muddled, and contradictory way. If we are not persuaded of this conceptual link 
and we read Ennis to be making more modest claims than McPeck attributes to him, most of McPeck's criticisms fall by the wayside.

Let us look more closely then at McPeck's model and its implications. It depends upon the plausibility of placing any line of thought into a "category," "domain," "subject area," or "field," which placement provides, implicitly or explicitly, criteria for judging it that line of thought. It tacitly assumes that all thinking is in one and only onecategory, that we can, without appealing to an expert on experts, tell what the appropriate category is, and thus what specialized information or skills are unique to it. Each discrete category creates the possibility for specialized concepts, experience, skills, etc. and for some limited set of people to develop the necessary wherewithal to think critically within it. Since there is a large number of logical domains and we can be trained only in a few of them, it follows that we must use our critical judgment mainly to suspend judgment and/or to defer to experts when we ourselves are not expert. It leaves little room for the classical concept of the liberally educated person as having skills of learning that are general and not domain specific. It is worthwhile therefore to set out more particularly, if somewhat abstractly, why it is unacceptable.

First of all the world is not given to us sliced up into logical categories, and there is not one, but an indefinitely large number of ways in which we may "divide" it, that is, experience, perceive, or think about the world, and no "detached" point of view from the supreme perspective of which we can decide on the appropriate taxonomy for the "multiple realities" of our lives. Conceptual schemes create logical domains and it is human thought, not nature, that creates them.

Second, our conceptual schemes themselves can be classified in an in- definitely large number of ways. To place a line of reasoning into a category and so to identify it by its "type" is heuristic, not ontological. Even concepts and lines of reasoning clearly within one category are also simultaneous within others. Most of what we say and think, to put it another way, is not only open-but-multi-textured as well. For example, in what logical domain does the (technical?) concept of alcoholism solely belong: disease, addiction, crime, moral failing, cultural pattern, lifestyle choice, defect of socialization, self-comforting behavior, psychological escape, personal weakness, ...? How many points of view can be used to illuminate it? Then, is each of them in one or many categories?

Not only conceptualizing "things," but most especially classifying what we have conceptualized, are not matters about which we can give the final word to experts and specialists. To place something said or thought into a category, from the perspective of which we intend to judge it, is to take a potentially contentious position with respect to it. There are no specialists who have the definitive taxonomy or undebatable means for so deciding. The category a thing is in is logically dependent upon what it is like, but all things (including conceptual schemes) are like any number of other things (other conceptual schemes for example) in any number of ways and so are in, dependent on our purposes, any number of logical domains.

Consider for example Copernicus' statements about the earth in relation to the sun. These are, you may be tempted to say, astronomical statements and nothing else. But if they become a part of concepts and lines of thought that have radically reoriented philosophical, social, religious, economic, and personal thought, as indeed they have, are they merely in that one category? When we begin to think in a cross-categorical way, as the intellec- 
tual heirs of Copernicus, Darwin, Freud, and Marx, are there categoryspecific skills and specialists to interpret that thought and tell us what the correct synthesis of these ingredients is and how it ought to color or guide our interpretation or critical assessment of statements "within" some particular domain or other?

The most important place that knowledge has in any lives is, on my view, that of shaping our concept of things überhaupt, our system of values, meanings, and interpretive schemes. This is the domain in which critical thought is most important to us. We spend only a small percentage of our lives making judgments as specialists, and even then we typically give a broader meaning to those acts as persons and citizens. Hence a business person may place a high value on her professional acts as contributing to the social good. She may interpret and assess the schools and education on the model of a business. She may judge the political process in its relation to the business community and see business opportunities and freedom as conceptually interrelated. She may then unfavorably judge societies not organized so as to favor "free investment of capital" as dangerous threats to human well being, and other such judgments. Logical synthesis, cutting across categories, extracting metaphors from one domain and using them to organize others, arguing for or against the global metaphors of others, are intellectual acts that are grounded ultimately not in the criteria and skills of specialists, not in some science or other or any combination thereof, but in the art of rationaldialectical-critical thought, in the art of thinking of anything in its "right" relationship to things überhaupt.

Hence, if we are to be rational agents, we must learn to think critically about how we "totalize" our experience and bring that total picture to bear on particular dimensions of our lives. We cannot, without losing our autonomy delegate the construction of those crucial acts to specialists or technicians. Students, teachers, and persons in general, need to maintain their critical autonomy even in, especially in, the face of specialists and even with respect to claims made within specialized areas. If democracy is a viable form of government and way of life then judgments not only of policy but of world view are the common task of all, not the prerogative of privileged groups of specialists. We need to pay special attention to those general skills of critical-cross-examination, for they are what enable us to maintain our autonomous judgment in the midst of experts. These pay-off skills, of civic literacy and personal autonomy, can be articulated best not in "procedures" that read like a technical manual but in "principles" that will often sound platitudinous or have the ring of "gene-

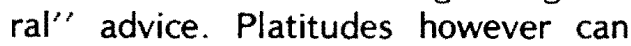
become insights and insights definitive of general skills when systematic caseby-case practice is supported by careful argument for and against. It is a platitude to say, for example, that the press and the media of a nation tend to cover the news so as to foster or presuppose the correctness of the "world view" of that nation or its government. But this bit of "common knowledge" is a far cry from the very important general skill of reading a newspaper so as to note how, where, and when it is insinuating nationalistic biases. Or again, it is one thing to recognize that all "news" is news from a point of view. It is another thing to be able to read or hear it with the critical sensitivity that enables one to see one point of view presupposed and others ruled out. McPeck thinks otherwise:

... where there is only common knowledge, there can only be common criticism-which is usually plain enough for one and all to see. This view not only represents a very shallow, or super- 
ficial, understanding of the cognitive ingredients of critical thinking, but it is also forced to underestimate and play down the real complexities that usually underlie even apparently 'common' or 'everyday' problems. The solutions to 'common', 'everyday' problems, if they are in fact problems, are seldom common or everyday. In any event, the educational aspirations of our schools are (fortunately) set higher than the treatment of issues that could otherwise be solved by common sense. Where common sense can solve a problem, there is hardly a need for special courses in critical thinking. And where common sense cannot solve a problem, one quickly finds the need for subject-specific information; hence, the traditional justification for subject-oriented courses. (pp. 156-157)

On my view the logics we use, and which we are daily constructing and reconstructing, are far more mutable, less discrete, more general, more openand multi-textured, more social, more dialectical, and even more personaland hence far less susceptible to domain-specific skills and concepts - than McPeck dares to imagine. We need to base our model of the critical thinker not on the domain-bound individual with subject-specific skills but on the disciplined generalist. This means that we ought to encourage the student as soon as possible to recognize that in virtually every area of our lives, cutting across categories every-which way, there are multiple conflicting viewpoints and theories vying for our allegience, virtually all of whose possible truth call for shifts in our global perspective. The general skills necessary to finding our way about in this dialectical world are more appropriately captured in the work of an Ennis, a D'Angelo, or a Scriven that a McPeck. General critical skills and dispositions cannot be learned without content, without doubt, but few would disagree with this point, certainly not Ennis, D'Angelo, or Scriven. The real and pressing question is not whether or not content is necessa- ry to thought (it is), but whether "content" restricts us to thinking "within" as against "across" and "between" and "beyond" categories. If there is such a thing as having a global perspective, and if that perspective not only sets out categories but also their taxonomy, and if such a perspective can be assessed only by appeal to general dialectical skills, not domain or subject-specific ones, then McPeck's vision of critical thinking instruction is fundamentally flawed and the move to a greater emphasis on critical thinking in education is more challenging, and to some perhaps more threatening, than has generally been recognized up to now. [5]

\section{Notes}

[1] In addition there is a growing number of national and international conferences on the subject, for example, the First and Second International Symposium on Informal Logic, the First and Second National Conference on Critical Thinking, Moral Education, and Rationality, and the First International Conference on Critical Thinking, Education, and the Rational Person.

[2] Blair and Johnson, eds., Informal Logic, The Proceedings of the First International Conference on Informal Logic. Pt. Reyes, CA: Edgepress, 1980.

[3] Such a course is now a graduation requirement for all California State College and University system students, as well as for the California Community College system.

[4] Robert Ennis, "A Concept of Critical Thinking." Harvard Educational Review, 1962.

[5] Something should be said in passing about McPeck's treatment of Edward de Bono to whose ideas he devotes a 
full chapter. This is odd, given the book's supposed focus on critical thinking, for de Bono has no theory of critical thinking as such, unless his stereotype of critical thinking as uncreative fault-finding qualifies as such. Indeed, de Bono uses the concept of critical thinking merely as a foil for "lateral" or "creative" thinking, which he of course takes to be essentially different. He holds that we already put too great an emphasis on critical thought. Perhaps McPeck includes him because of his celebrity. I find this inclusion inappropriate and the amount of attention devoted to him unjustified, if critical thinking is indeed McPeck's concern. Furthermore, de Bono is clearly not in the same league theoretically as an Ennis, D'Angelo, or Scriven whatever his celebrity, and his kaleidoscopic, helter-skelter development of metaphors, which merely suggest rather than theoretically probe the character of "lateral" thought, is an easy target for critique.

Dr. Richard W. Paul, Director, Center for Critical Thinking and Moral Critique, Sonoma State University, Rohnert Park, CA 94928. 